\title{
Two-stage, school and community-based population screening successfully identifies individuals and families at high-risk for type 2 diabetes: the Feel4Diabetes-study
}

Yannis Manios ${ }^{1 *}$, Christina Mavrogianni ${ }^{1}$, Christina-Paulina Lambrinou ${ }^{1}$, Greet Cardon ${ }^{2}$, Jaana Lindström ${ }^{3}$, Violeta lotova ${ }^{4}$, Tsvetalina Tankova $^{5}$, Fernando Civeira ${ }^{6}$, Jemina Kivelä ${ }^{3}$, Zoltán Jancsó ${ }^{7}$, Samyah Shadid ${ }^{8}$, Kaloyan Tsochev ${ }^{4}$, Rocío Mateo-Gallego ${ }^{9}$, Sándorné Radó ${ }^{7}, G^{\prime}$ George Dafoulas ${ }^{10}$, Konstantinos Makrilakis ${ }^{10}$, Odysseas Androutsos ${ }^{11}$ and on behalf of the Feel4Diabetes-study group

\begin{abstract}
Background: The implementation of population screening and early prevention strategies targeting individuals at high-risk for type 2 diabetes (T2D) seems to be a public health priority. The current work aimed to describe the screening procedure applied in the Feel4Diabetes-study and examine its effectiveness in identifying individuals and families at high risk, primarily for T2D and secondarily for hypertension, among vulnerable populations in low to middle-income countries (LMICS) and high-income countries (HICS) across Europe.

Methods: A two-stage screening procedure, using primary schools as the entry-point to the community, was applied in low socioeconomic status (SES) regions in LMICs (Bulgaria-Hungary), HICs (Belgium-Finland) and HICs under austerity measures (Greece-Spain). During the first-stage screening via the school-setting, a total of 20,501 parents (mothers and/or fathers) of schoolchildren from 11,396 families completed the Finnish Diabetes Risk Score (FINDRISC) questionnaire, while their children underwent anthropometric measurements in the school setting. Parents from the identified "high-risk families" ( $n=4484)$ were invited to participate in the second-stage screening, including the measurement of fasting plasma glucose (FPG) and blood pressure (BP). In total, 3153 parents participated in the second-stage screening (mean age $41.1 \pm 5.6$ years, $65.8 \%$ females).
\end{abstract}

Results: Among parents who attended the second-stage screening, the prevalence of prediabetes (as defined by impaired fasting glucose; FPG 100-125 mg/dl) and T2D (FPG > $126 \mathrm{mg} / \mathrm{dl}$ ) was 23.2 and 3.0\% respectively, and it was found to be higher in the higher FINDRISC categories. The percentage of undiagnosed T2D among the participants identified with T2D was 53.5\%. The prevalence of high normal BP (systolic BP 130-139 mmHg and/ or diastolic BP 85$89 \mathrm{mmHg}$ ) and hypertension (systolic BP $\geq 140 \mathrm{mmHg}$ and/ or diastolic BP $\geq 90 \mathrm{mmHg}$ ) was 14 and $18.6 \%$ respectively, which was also higher in the higher FINDRISC categories. The percentage of cases not receiving antihypertensive treatment among the participants identified with hypertension was $80.3 \%$.

(Continued on next page)

\footnotetext{
* Correspondence: manios.feel4diabetes@hua.gr

'Department of Nutrition and Dietetics, School of Health Science and Education, Harokopio University, 70 El Venizelou Ave, 17671 Kallithea, Athens, Greece

Full list of author information is available at the end of the article
}

(c) The Author(s). 2020 Open Access This article is distributed under the terms of the Creative Commons Attribution 4.0 International License (http://creativecommons.org/licenses/by/4.0/), which permits unrestricted use, distribution, and reproduction in any medium, provided you give appropriate credit to the original author(s) and the source, provide a link to the Creative Commons license, and indicate if changes were made. The Creative Commons Public Domain Dedication waiver (http://creativecommons.org/publicdomain/zero/1.0/) applies to the data made available in this article, unless otherwise stated. 
(Continued from previous page)

Conclusion: The findings of the current study indicate that the two-stage school and community-based screening procedure followed, effectively identified high-risk individuals and families in vulnerable populations across Europe. This approach could be potentially scalable and sustainable and support initiatives for the early prevention of T2D and hypertension.

Trial registration: The Feel4Diabetes-intervention is registered at https://clinicaltrials.gov/ (NCT02393872; date of trial registration: March 20, 2015).

Keywords: Screening, School-based, Vulnerable groups, Type 2 diabetes, Hypertension

\section{Background}

Diabetes affects around $8.8 \%$ of the adult population worldwide, and the total number of cases is predicted to rise from 425 million in 2017 to 629 million in 2045 [1]. T2D accounts for about $90 \%$ of all cases of diabetes and it is an important cause of mortality and morbidity, with its complications imposing a great burden both on individuals and healthcare systems $[1,2]$. Furthermore, there is an elevated risk of developing T2D in vulnerable populations with disadvantaged socioeconomic background, probably due to the higher prevalence of unhealthy lifestyles in deprived communities and the barriers to access health care [3-5]. Based on evidence from several clinical trials, T2D is preventable through lifestyle intervention provided to individuals at increased risk $[6,7]$, while early detection of T2D may prevent mortality and complications $[8,9]$. Thus, the implementation of screening strategies for the identification of high-risk individuals, coupled with non-pharmacological interventions becomes a public health priority.

The modifiable risk factors related to T2D (e.g. overweight/ obesity, physical inactivity, unhealthy dietary habits) that are developed in childhood and track into adulthood $[10,11]$, potentially increase the future T2D risk. Furthermore, these risk factors tend to cluster within a family, as its members share common genetic background, but also lifestyle, social and physical environment. In this context, interventions targeting families could be potentially more effective since the whole family becomes more supportive in adopting the desired behavior changes [12, 13]. Therefore, trying to identify families at high risk for developing T2D and invite them to take part in prevention programs could be a promising and potentially cost-effective approach, since at least two generations (i.e. parents and children) can be targeted simultaneously.

Using a two-stage screening procedure to identify individuals having or being at high risk of developing T2D is an easy to apply and cost-effective approach [14]. Furthermore, this approach seems to have an increased response rate compared to other multi-stage screening strategies [15] and is proposed by the guidelines of several international health organizations $[16,17]$. During the first stage, a non-invasive assessment of risk with a self-reported diabetes risk evaluation tool is applied. Such a tool is the FINDRISC [18], which is the most widely used tool in Europe for estimating the future T2D risk. In the second stage, a diagnostic test (fasting glucose, oral glucose tolerance test [OGTT] or glycated hemoglobin [HbA1c]) is performed, but only among those individuals categorized as high-risk in the previous stage.

Although the two-stage screening has been used before in previous studies, in the vast majority of them its implementation was opportunistic, including individuals visiting healthcare services or applying door-to-door procedures [15]. However, this approach seems to be less effective in reaching and screening less healthconscious individuals, early middle-aged adults and vulnerable population groups, such as low SES groups [19]. Therefore if we want to reach such populations, an alternative systematic, low-cost and potentially sustainable approach needs to be considered. School setting could facilitate this need and serve as the entry-point to the community, in order to identify "high-risk families".

Considering the above, the Feel4Diabetes consortium, developed and implemented for the first time a twostage screening procedure targeting vulnerable families in six European countries. Primary schools were used as the entry-point to the community, aiming to reach and screen the targeted population (children and their families). The primary aim of the current work was to describe the procedure of the Feel4Diabetes-screening and present the relevant results in terms of identifying individuals and families at high risk for T2D. Furthermore, since T2D and hypertension share common comorbidities and risk factors [20], the secondary aim of the current work was to examine whether the screening procedure followed could identify also individuals and families at high risk for hypertension.

\section{Methods}

\section{Study background}

The current work used the baseline data of the EUfunded Feel4Diabetes-study (http://feel4diabetes-study. $\mathrm{eu} /$ ), which aimed to develop, implement and evaluate a school- and community-based intervention to prevent T2D among families from vulnerable groups across Europe. A detailed description of the study design has been previously published [21]. Recruitment started in 
January 2016 and measurements were conducted between April and June in Belgium, Greece and Spain, while for Finland, Hungary and Bulgaria measurements were extended to September 2016. The Feel4Diabetes-study was registered at clinicaltrials.gov as NCT02393872.

\section{Recruitment}

Recruitment was based on a standardized, multi-stage sampling procedure and was conducted within selected provinces in six European countries. The participating countries are categorized in three socioeconomic levels according to the World Bank country classification based on Gross National Income (GNI) per capita [22] and the Eurostat's Government Budget Deficit data in 2014 [23]. Specifically the participating countries were grouped as follows: LMICs (i.e. Bulgaria and Hungary), HICs (i.e. Belgium and Finland) and HICs under austerity measures (i.e. Greece and Spain). Since the prevalence of T2D tends to be higher in LMICs [24], any municipality, school district or other equivalent unit in Bulgaria and Hungary was considered as "vulnerable" area and eligible to participate in the study. Regarding HICs, as low SES has been associated with increased risk of T2D in these countries [3], only low SES regions were considered as "vulnerable" in Belgium, Finland, Greece and Spain. Specifically, in these countries low SES regions were defined using the following steps: (i) the municipalities, school districts or other equivalent units in the selected provinces were grouped in tertiles according to SES indices (i.e. literacy or unemployment rates) retrieved from official resources and relevant authorities [25-28] and (ii) "vulnerable" areas were randomly selected only from the tertile with the lowest SES indices.

In each country, primary schools located in the selected "vulnerable" areas were used as the entry-point to the community. Children attending the first three grades of compulsory education as well as their parents and grandparents (wherever feasible) were recruited to the study. Of these recruited families, the "high-risk families" were identified based on T2D risk estimation, using the FINDRISC questionnaire. A family was regarded as "high-risk" if at least one parent fulfilled the countryspecific cut-off point for FINDRISC that indicated increased T2D risk (for the majority of countries, considering the young age of the participants, that was set as a FINDRISC score $\geq 9$ ).

\section{First-stage screening}

In the participating schools, teachers distributed the standardized study questionnaire to all children in the class to be delivered to their parents/ caregivers [29]. Families were requested to return the completed questionnaires in sealed envelopes, and the children from the participating families underwent anthropometric measurements at school, conducted by trained research assistants [30].

\section{Measurements conducted during the first-stage screening Questionnaires}

Data regarding children's and parents' eating, physical activity and sedentary behaviors, and parents' sociodemographic data were collected, while both parents were requested to complete the FINDRISC questionnaire. The most recent version of it consists of eight scored questions that cover the well-known risk factors of T2D, i.e. age, body mass index (BMI), waist circumference (WC), daily physical activity, daily consumption of vegetables and fruits/ berries, use of antihypertensive medication, individual's history of high blood glucose, and family history of diabetes [31]. The total score indicates the individual's 10-year risk of developing T2D and ranges from 0 to 26, as follows: $<7$ (low), 7-11 (slightly elevated), 12-14 (moderate), 15-20 (high) and $>20$ (very high). In order to facilitate the assessment of $\mathrm{WC}$, a paper waist measuring tape was provided to each family.

\section{Anthropometry}

Body weight was measured to the nearest $0.1 \mathrm{~kg}$ and children were weighed in light clothing and without shoes. Height was measured to the nearest $0.1 \mathrm{~cm}$ with the children standing barefoot, keeping shoulders in a relaxed position, arms hanging freely and head in Frankfurt horizontal plane. Two readings were obtained out of each measurement and the mean was used for the analysis. A third measurement was conducted if the previous measurements differ $>100 \mathrm{~g}$ for weight and $>1 \mathrm{~cm}$ for height. Weight and height were used to calculate BMI using Quetelet's equation [weight $(\mathrm{kg}) /$ height $(\mathrm{m})^{2}$ ] . The International Obesity Task Force (IOTF) cutoff points [32] were used to categorize children as "underweight", "normal weight", "overweight", or "obese".

\section{Second-stage screening}

Following the first-stage screening and after calculating the FINDRISC scores and identifying the "high-risk families", researchers contacted these families in a discrete manner (to avoid stigmatization of children/ families) and invited them to attend the second-stage screening, which was conducted outside the school setting. Specifically, all parents and grandparents (wherever feasible) of the identified "high-risk families" were invited to undergo a brief medical check-up delivered in local community centers or during home visits (in certain cases in Belgium). In all countries, measurements were conducted by trained research assistants [30], using standardized protocols and calibrated equipment. The 
current work focuses on the early identification of T2D and hypertension among parents (early middle-aged adults) and therefore grandparents' data were excluded from the statistical analysis and relevant tables.

\section{Measurements conducted during the second-stage screening Blood indices}

Blood samples were drawn in the morning after overnight fasting for at least $8 \mathrm{~h}$. Participants (parents and grandparents where feasible) were contacted via phone calls on the previous day to ensure compliance with fasting. Moreover, they were advised to refrain from taking their medications in the morning when the blood collection was performed. Fasting plasma glucose (FPG) was analyzed in accredited laboratories, using similar enzymatic assays in all study centers. Participants were classified according to the American Diabetes Association (ADA) criteria [33] in the following categories: normal (FPG $<100 \mathrm{mg} / \mathrm{dl} ; 5.6 \mathrm{mmol} / \mathrm{l}$ ), prediabetes (FPG 100$125 \mathrm{mg} / \mathrm{dl} ; 5.6-6.9 \mathrm{mmol} / \mathrm{l})$ and T2D (FPG $\geq 126 \mathrm{mg} / \mathrm{dl}$; $7.0 \mathrm{mmol} / \mathrm{l})$.

\section{Blood pressure measurement}

Blood pressure (BP) was measured on the right arm, in a sitting position using an Omron digital blood pressure measuring device (OMRON M6 or M6 AC) after 5 min of rest, on three occasions, allowing 1 min interval among the occasions. Participants were asked to avoid vigorous exercise, smoking, eating or drinking for $1 \mathrm{~h}$ before the BP measurement. Means of the second and third measurements were used in the current statistical analysis. Participants were classified according to the European guidelines [34] in the following categories: optimal or normal (systolic $\mathrm{BP}<130 \mathrm{mmHg}$ and/ or diastolic $\mathrm{BP}<85 \mathrm{mmHg}$ ), high normal (systolic BP 130-139 $\mathrm{mmHg}$ and/ or diastolic BP $85-89 \mathrm{mmHg}$ ) and hypertension (systolic $\mathrm{BP} \geq 140 \mathrm{mmHg}$ and/ or diastolic $\mathrm{BP} \geq 90$ $\mathrm{mmHg}$ ), with the BP category to be defined by the highest level of BP, either systolic or diastolic.

\section{Anthropometry}

Body weight and height were measured in light clothing and without shoes to the nearest $0.1 \mathrm{~kg}$ and $0.1 \mathrm{~cm}$ respectively, and WC was measured midway between the lowest rib margin and the iliac crest to the nearest 0.1 $\mathrm{cm}$. Portable equipment was used [for weight: digital scales (SECA 813 or 877), for height: telescopic stadiometers (SECA 213 or 214 or 217 or 225), for WC: nonelastic tapes (SECA 201)]. Two readings were obtained out of each measurement and the mean was used for the analysis. A third measurement was conducted if the previous measurements differ $>100 \mathrm{~g}$ for weight, $>1 \mathrm{~cm}$ for height and $>1 \mathrm{~cm}$ for WC. BMI and WC were classified based on the World Health Organization (WHO) criteria [35].

\section{Questionnaires}

Besides data related to lifestyle factors, sociodemographic data (e.g. age, gender, education, occupation) and information regarding medical history and medication use were collected from participants (parents and grandparents where feasible). Specifically, previous diabetes diagnosis was assessed by the question "Has a physician ever told you that you have diabetes?", while medication-treated hypertension was assessed by the question "Do you currently use drugs for high BP prescribed by a physician?" (Possible answers: yes, no).

\section{Statistical analysis}

In the current work the participating countries were grouped in regions as: HICs (Belgium and Finland), HICs under austerity measures (Greece and Spain) and LMICs (Bulgaria and Hungary). A descriptive statistical analysis was performed by using the Statistical Package for Social Sciences (SPSS Inc., Chicago, IL, USA), version 21.0. Continuous variables are presented as means \pm standard deviations and categorical values as proportions (\%). Differences in continuous variables were assessed by parametric (One-Way Analysis of Variance) or nonparametric tests (Kruskall-Wallis), according to the distribution of the variables (Kolmogorov-Smirnoff test), while Pearson's Chi-square test was used to evaluate the differences in proportions. All statistical tests were two-tailed and the level of statistical significance was set at $P<0.05$.

\section{Results}

The population reached in the Feel4Diabetes-study is presented in Table 1. Overall, 28,075 families were contacted via the participating 219 primary schools. During the first-stage screening that was delivered via the school setting with the completion of a self-reported screening tool (i.e. FINDRISC), 11,396 families were screened for T2D risk. All parents and/or grandparents of those families identified with increased risk were invited to the second-stage screening (a more detailed medical examination) and finally at least one adult from 2537 "highrisk families" was measured at baseline, with data available for 3153 parents.

The descriptive characteristics of the parents and children of the "high-risk families" that participated in the second-stage screening, stratified by region are presented in Table 2. Parents were aged $41.1 \pm 5.6$ years and $65.8 \%$ were females. Overall, $65.8 \%$ of parents were full-time employed; while $23.6 \%$ of them had less than 12 years of education, with the latter being lower in HICs. The prevalence of overweight and obesity was 35.3 and 
Table 1 Population reached and screened in the "Feel4Diabetes-study"

\begin{tabular}{|c|c|c|c|c|c|c|c|}
\hline \multirow[t]{2}{*}{ Number of } & \multirow[t]{2}{*}{$\begin{array}{l}\text { All } \\
\text { countries }\end{array}$} & \multicolumn{2}{|c|}{$\begin{array}{l}\text { HICs under } \\
\text { austerity measures }\end{array}$} & \multicolumn{2}{|l|}{ LMICs } & \multicolumn{2}{|l|}{ HICs } \\
\hline & & Greece & Spain & Bulgaria & Hungary & Belgium & Finland \\
\hline Participating schools & 219 & 56 & 41 & 20 & 14 & 58 & 30 \\
\hline Families contacted via participating schools & 28,075 & 5195 & 4823 & 6541 & 2902 & 5367 & 3247 \\
\hline Families participated in the "first-stage screening" & 11,396 & 2096 & 1567 & 2948 & 1762 & 1684 & 1339 \\
\hline Parents provided completed FINDRISC questionnaires ("first-stage screening") & 20,501 & 3741 & 3043 & 5211 & 3034 & 2990 & 2482 \\
\hline Children measured at school setting (anthropometric indices obtained) & 12,194 & 2286 & 1703 & 3034 & 1867 & 1798 & 1506 \\
\hline $\begin{array}{l}\text { Families identified as "high risk families" and invited to participate in the } \\
\text { "second-stage screening" }\end{array}$ & 4484 & 907 & 715 & 1088 & 689 & 475 & 610 \\
\hline Families participated in the "second-stage screening" & 2537 & 452 & 541 & 463 & 286 & 420 & 375 \\
\hline Parents participated in the "second-stage screening" & 3153 & 696 & 659 & 554 & 319 & 499 & 426 \\
\hline Grandparents participated in the "second-stage screening" & 121 & 69 & - & 46 & 1 & 5 & - \\
\hline
\end{tabular}

FINDRISC Finnish Diabetes Risk Score, HICs High-income countries, LMICs Low to middle-income countries

$36.7 \%$, respectively, in the total sample and it was found to be lower in LMICs compared to other regions. Finally, among the participating "high-risk families", 2711 children (aged $8.16 \pm 1.0$ years; $51.1 \%$ girls) were measured.

The prevalence of prediabetes and T2D among the parents that participated in the second-stage screening is presented in Table 3. According to the measured FPG and the ADA criteria, the overall prevalence of prediabetes was $23.2 \%$, while for $\mathrm{T} 2 \mathrm{D}$ it was $3.0 \%$. A marked higher prevalence of prediabetes and T2D was observed in parents with higher FINDRISC $(P<0.001)$ in all countries, as well as in each region (Fig. 1). Overall, among those parents identified with T2D, 53.5\% of participants were previously undetected, with this percentage being

Table 2 Descriptive characteristics of parents and children of families participated in the second-stage screening by region

\begin{tabular}{|c|c|c|c|c|c|}
\hline & Total sample & HICs under austerity measures & LMICS & $\mathrm{HICS}$ & $P$-value* \\
\hline Parents & $(n=2849)$ & $(n=1385)$ & $(n=624)$ & $(n=840)$ & \\
\hline Age (years) & $41.1(5.56)$ & $42.4(5.32)^{a, b}$ & $39.6(5.40)^{a}$ & $40.1(5.60)^{b}$ & $<0.001$ \\
\hline Females, n (\%) & $1875(65.8)$ & $837(60.4)^{a, b}$ & $464(74.4)^{a}$ & $574(68.3)^{b}$ & $<0.001$ \\
\hline \multicolumn{6}{|l|}{ Occupation, n (\%) } \\
\hline Work full- time & 1875 (65.8) & $885(63.9)^{\mathrm{a}}$ & $445(71.3)^{a, b}$ & $545(64.8)^{b}$ & \multirow[t]{6}{*}{$<0.001$} \\
\hline Work part- time & $335(11.7)$ & $154(11.1)^{a, b}$ & $41(6.5)^{\mathrm{b}, \mathrm{c}}$ & $140(16.7)^{a, c}$ & \\
\hline Stay at home parent & $345(12.1)$ & $203(14.7)^{\mathrm{a}}$ & $83(13.3)^{b}$ & $59(7.0)^{\mathrm{a}, \mathrm{b}}$ & \\
\hline Unemployed & $139(4.9)$ & $112(8.1)^{a, b}$ & $8(1.3)^{a}$ & $19(2.3)^{\mathrm{b}}$ & \\
\hline Full-time education & $31(1.1)$ & $4(0.3)^{a, b}$ & $8(1.3)^{\mathrm{a}}$ & $19(2.3)^{b}$ & \\
\hline Other ${ }^{* *}$ & $124(4.4)$ & $27(1.9)^{a, b}$ & $39(6.3)^{a}$ & $58(6.9)^{b}$ & \\
\hline \multicolumn{6}{|l|}{ Educational level, n (\%) } \\
\hline$<12$ years & $673(23.6)$ & $373(26.9)^{a}$ & $160(25.6)^{b}$ & $140(16.7)^{a, b}$ & \multirow[t]{2}{*}{$<0.001$} \\
\hline$\geq 12$ years & $2176(76.4)$ & $1012(73.1)^{\mathrm{a}}$ & $464(74.4)^{\mathrm{b}}$ & $700(83.3)^{a, b}$ & \\
\hline \multicolumn{6}{|l|}{ Weight status, n (\%) } \\
\hline Overweight & $1006(35.3)$ & $506(36.5)^{a}$ & $185(29.6)^{a, b}$ & $315(37.5)^{b}$ & \multirow[t]{3}{*}{$<0.001$} \\
\hline Obese & $1045(36.7)$ & $550(39.7)^{a}$ & $203(32.6)^{a}$ & $292(34.8)$ & \\
\hline Children & $(n=2711)$ & $(n=1089)$ & $(n=753)$ & $(n=869)$ & \\
\hline Age (years) & $8.16(1.02)$ & $7.80(0.93)^{a, b}$ & $8.43(1.00)^{a}$ & $8.36(1.00)^{b}$ & $<0.001$ \\
\hline Females, n (\%) & $1385(51.1)$ & $549(50.4)$ & $393(52.2)$ & $443(51.0)$ & 0.752 \\
\hline
\end{tabular}

Data are means (SD) except where noted otherwise

" $P$-values indicate the significance of the differences among regions

Figures sharing the same superscript letters differentiate significantly from each other

"Other includes "retired" and "something else"

HICs High-income countries, LMICs Low to middle-income countries 
Table 3 Prevalence of prediabetes and diabetes in parents participated in the second-stage screening

\begin{tabular}{|c|c|c|c|c|c|c|c|}
\hline & \multirow{3}{*}{$\begin{array}{l}\text { I } \\
\text { Participants } \\
\text { identified with } \\
\text { prediabetes, n (\%) }\end{array}$} & \multirow{3}{*}{$\begin{array}{l}\text { II } \\
\text { Participants } \\
\text { identified with } \\
\text { diabetes, n (\%) }\end{array}$} & \multirow{3}{*}{$\begin{array}{l}\text { III } \\
\text { Participants for whom diabetes } \\
\text { was previously undetected among } \\
\text { those identified with diabetes } \\
\text { in column } \|, \mathrm{n}(\%)^{* *}\end{array}$} & \multirow{2}{*}{\multicolumn{3}{|c|}{$\begin{array}{l}\text { IVParticipants as presented in } \\
\text { column III, stratified by } \\
\text { FINDRISC category }\end{array}$}} & \multirow{3}{*}{$\begin{array}{l}P \text { - } \\
\text { value* }\end{array}$} \\
\hline & & & & & & & \\
\hline & & & & $0-11$ & $12-14$ & $15-26$ & \\
\hline All countries $(n=2685)$ & $623(23.2)$ & $81(3.0)$ & $40(53.5)$ & $13(81.3)^{a}$ & $13(64.7)$ & $14(36.8)^{a}$ & 0.007 \\
\hline $\begin{array}{l}\text { HICs under austerity measures } \\
(n=1249)\end{array}$ & $304(24.3)$ & $36(2.9)$ & $15(40.0)$ & $4(57.1)$ & $5(66.7)$ & $6(27.3)$ & 0.127 \\
\hline LMICs $(n=644)$ & $84(13.1)$ & $26(4.0)$ & $21(80.0)$ & $8(100.0)$ & $7(85.7)$ & $6(60.0)$ & 0.098 \\
\hline HICs $(n=792)$ & $235(29.6)$ & $19(2.4)$ & $4(36.4)$ & $1(100.0)$ & $1(25.0)$ & $2(33.3)$ & 0.368 \\
\hline
\end{tabular}

${ }^{*} P$-values indicate the significance of the differences among FINDRISC categories Figures sharing the same superscript letters differentiate significantly from each other

** The numbers provided for this variable in the case of HICs do not include data from Finland $(n=7)$, since participants with previously diagnosed diabetes were excluded from the study at this study center

FINDRISC Finnish Diabetes Risk Score, HICs High-income countries, LMICs Low to middle-income countries

lower in the highest FINDRISC category compared to the lowest one $(P=0.007)$.

The prevalence of high normal BP and hypertension among parents that participated in the second-stage screening are presented in Table 4 . The overall prevalence of high normal BP was $14.0 \%$, ranging from 12.7 and $16.7 \%$ to $15.7 \%$ for participants with FINDRISC score $\leq 11,12-14$ and $\geq 15$, respectively (Fig. 2). The prevalence of hypertension was $18.6 \%$ in the total sample, while $80.3 \%$ of the participants identified with hypertension were not receiving any antihypertensive treatment. The prevalence of hypertension was found to be higher in the higher FINDRISC categories compared to the lowest one (Fig. 2), while the percentage of participants not receiving any antihypertensive treatment among those identified with hypertension was found to be lower in the higher FINDRISC categories compared to the lowest ones $(P<0.001)$.

The prevalence of overweight or obesity in the children of "high-risk families" participating in the secondstage screening is presented in Table 5. This was found to be $28.2 \%$ in the total sample, with this percentage being higher if the parents were at higher T2D risk (i.e. at least one parent with FINDRISC score $12-14$ or $\geq 15$ vs. both parents with FINDRISC score $\leq 11, \mathrm{P}<0.001)$. The same trend was also observed for HICs under austerity measures, while no significant differences were found among parental FINDRISC categories for the other regions.

\section{Discussion}

In the Feel4Diabetes-study, a large number of families were screened and a relatively high number of parents were identified to be at high risk for T2D and hypertension via a two-stage screening procedure, trying to keep the cost as low as possible. That was realized via the use of available community infrastructure (primary schools and local municipality centers) and personnel (i.e. teachers and healthcare professionals wherever feasible). The current approach, using the school-setting as the entry-point to the community, can be a potentially costeffective and sustainable community-based approach for the early identification of high-risk individuals and families for T2D and hypertension and support relevant prevention initiatives. Overall, the implemented screening procedure as well as the definition and prioritization of vulnerable population-groups, could guide other similar strategies both in LMICs and HICs across Europe.

Considering the relatively young age $(41.1 \pm 5.6$ years) of the study population (i.e. parents of primary-school children), recruited in countries across Europe, the fact that about only $66 \%$ of them reported to be working full-time and almost $25 \%$ had less than 12 years of education, indicate that the aim of the Feel4Diabetes-study to target primarily vulnerable groups was achieved to a large extent. Selecting the most appropriate screening strategy to reach such a population (i.e. early middle-aged adults and populations in low SES areas) poses challenges for healthcare professionals. Although opportunistic screening for T2D among asymptomatic individuals has been recommended as the most efficient approach [36], this may lead to selection bias due to reaching the most motivated individuals. On the other hand, the door-to-door screening approach can target a large segment of the population, but it has been reported to have lower adherence to the diagnostic tests compared to opportunistic screening [37] and may not be a sustainable and easily scalable approach. To overcome these issues, the findings of the current study indicate that applying a two-stage screening using primary schools as the entry-point to the community can efficiently reach high-risk families/ individuals. Therefore, by embedding this procedure into the local or national school and local healthcare systems, a systematic, continuous and organized screening could be 


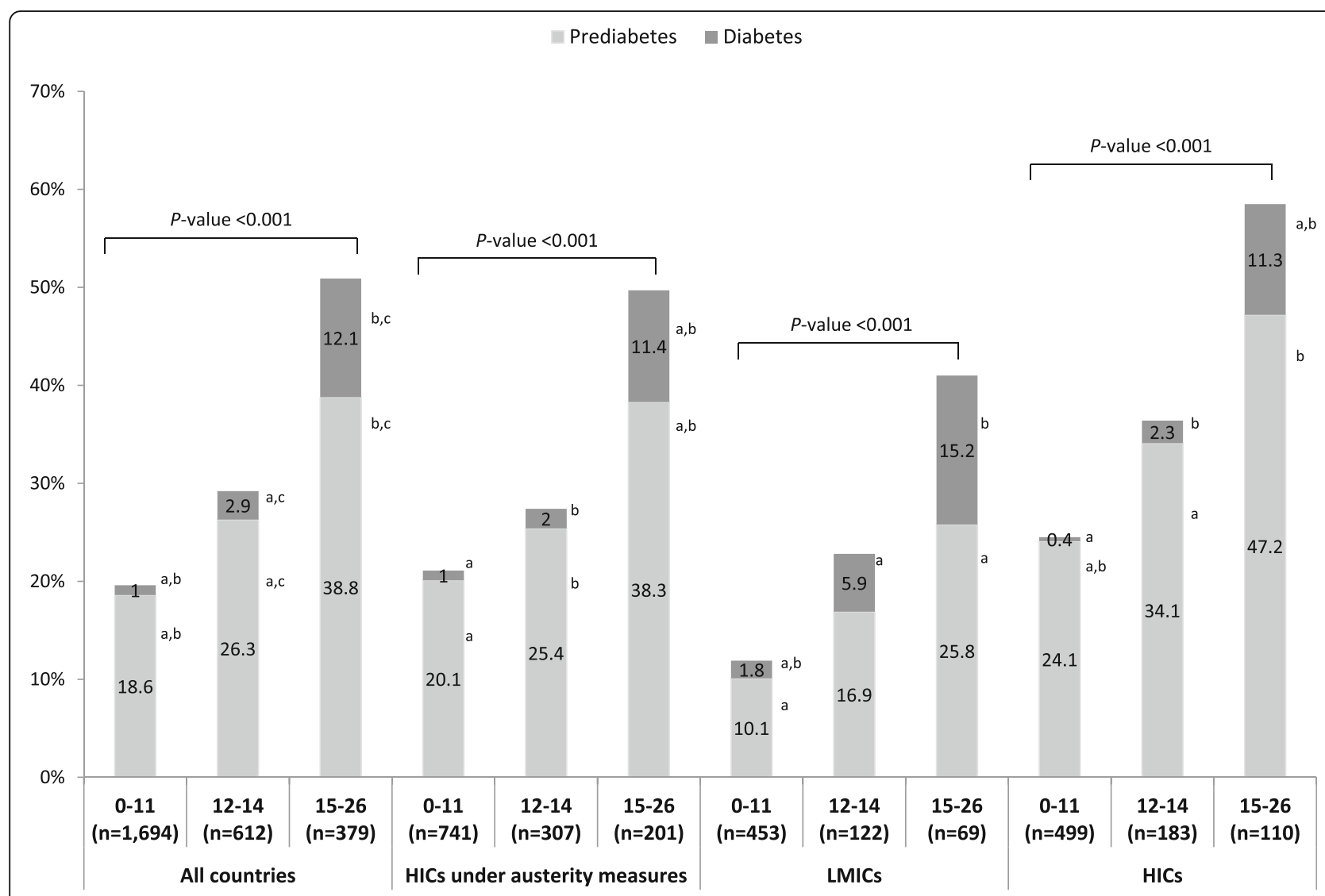

Fig. 1 Prevalence of prediabetes and diabetes in parents participated in the second-stage screening by FINDRISC category. P-values indicate the significance of the differences among FINDRISC categories: 0-11 (low and slightly elevated risk), 12-14 (moderate risk), 15-16 (high and very high risk). Figures sharing the same superscript letters differentiate significantly from each other. FINDRISC: Finnish Diabetes Risk Score; HICs: Highincome countries; LMICs: Low to middle-income countries

delivered at population level and potentially reach the largest part of the community.

The screening approach used in the Feel4Diabetesstudy managed to identify 3.0 and $23.2 \%$ of individuals with T2D and prediabetes, respectively, and these percentages were found to be increased in the higher
FINDRISC categories. These figures seem to be lower compared to findings from some other studies [38, 39], possibly due to the screening approach used in the current study (i.e. targeting the whole population and not only the health conscious ones or those attending healthcare services for other health issues), as well as the

Table 4 Prevalence of high normal blood pressure and hypertension in parents participated in the second-stage screening

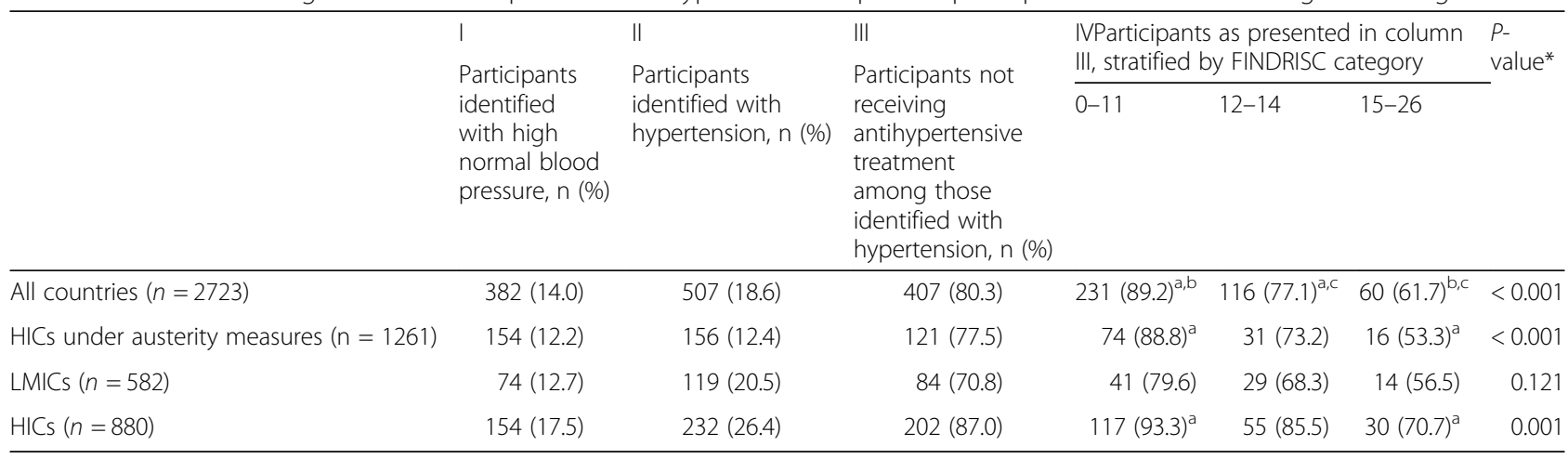

*P-values indicate the significance of the differences among FINDRISC categories

Figures sharing the same superscript letters differentiate significantly from each other

FINDRISC Finnish Diabetes Risk Score, HICs High-income countries, LMICs Low to middle-income countries 


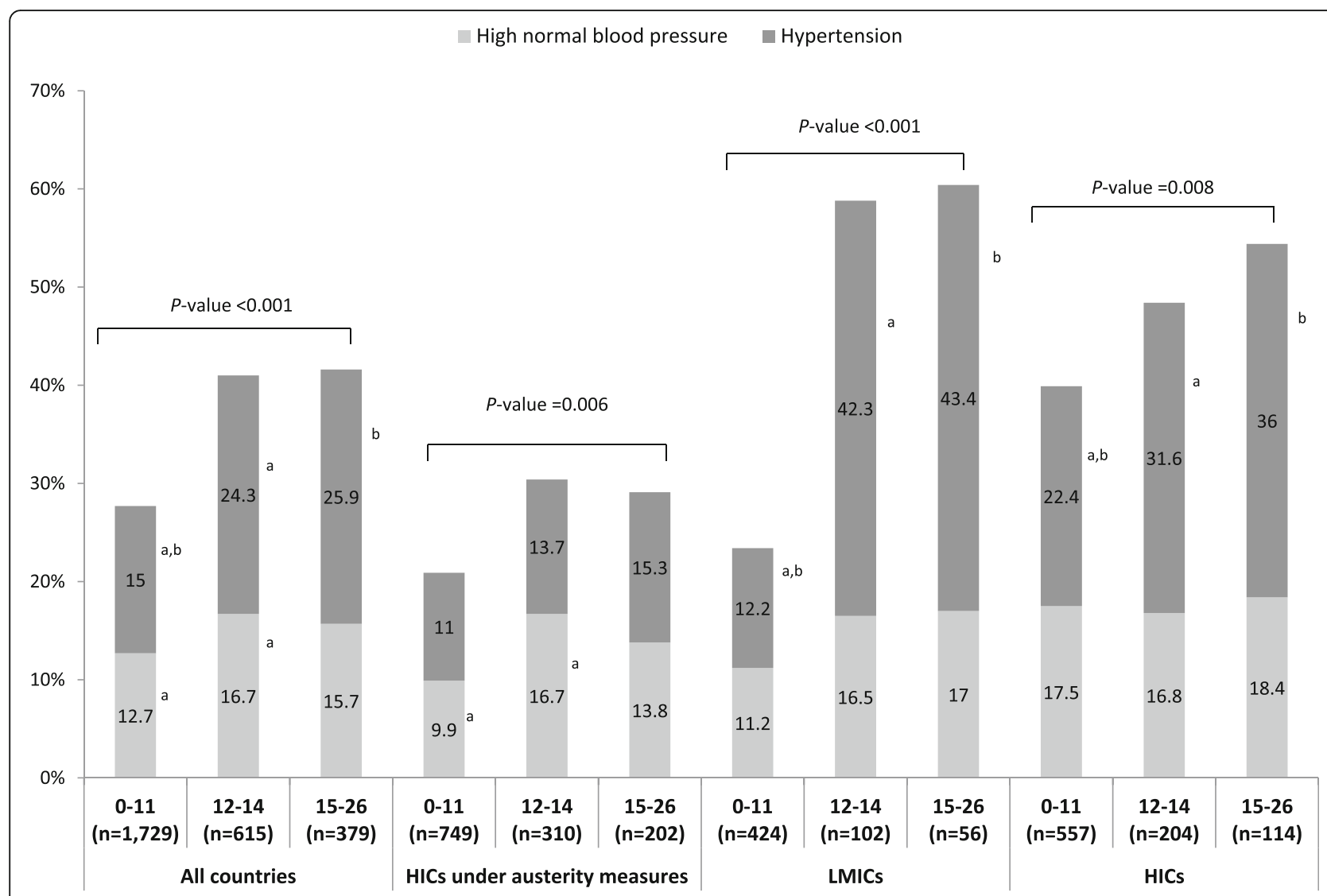

Fig. 2 Prevalence of high normal blood pressure and hypertension in parents participated in the second-stage screening by FINDRISC category. P-values indicate the significance of the differences among FINDRISC categories: 0-11 (low and slightly elevated risk), 12-14 (moderate risk), 1516 (high and very high risk). Figures sharing the same superscript letters differentiate significantly from each other. FINDRISC: Finnish Diabetes Risk Score; HICs: High-income countries; LMICs: Low to middle-income countries

younger age of the participants. Furthermore, $53.5 \%$ of cases identified with T2D were previously undetected. This is in accordance with current estimations indicating that almost half of all people with diabetes are undiagnosed [1]. It has been also reported that the FINDRISC questionnaire is considered valid for identifying individuals with undiagnosed T2D and dysglycaemia in the population under study, while "individuals' history of high blood glucose" was the FINDRISC component most strongly associated with both conditions [40]. In this context, the proportion of undetected T2D cases was found to be highest in the lowest FINDRISC category, probably because these individuals obtained a low score in the aforementioned FINDRISC component. To some extent this can be attributed to the fact that many of these participants may have not previously undergone

Table 5 Prevalence of overweight or obesity in children of families participated in the second-stage screening

\begin{tabular}{|c|c|c|c|c|c|}
\hline \multirow[t]{2}{*}{ Variables } & \multirow{2}{*}{$\begin{array}{l}\text { Total } \\
\text { sample }\end{array}$} & \multicolumn{3}{|c|}{ By parental FINDRISC category } & \multirow[b]{2}{*}{$P$-value* } \\
\hline & & Both parents $0-11$ & At least one parent 12-14 & At least one parent 15-26 & \\
\hline \multicolumn{6}{|l|}{ Overweight or obesity in children, n (\%) } \\
\hline All countries $(n=2231)$ & $630(28.2)$ & $267(24.5)^{a, b}$ & $213(31.4)^{\mathrm{a}}$ & $150(32.5)^{b}$ & 0.001 \\
\hline HICs under austerity measures $(n=930)$ & 309 (33.2) & $126(28.9)^{\mathrm{a}}$ & $100(35.1)$ & $83(39.7)^{a}$ & 0.018 \\
\hline LMICs $(n=616)$ & $175(28.4)$ & $73(24.6)$ & $64(32.7)$ & $38(30.9)$ & 0.119 \\
\hline $\mathrm{HICS}(n=685)$ & $146(21.3)$ & $68(19.0)$ & $49(24.9)$ & $29(22.3)$ & 0.258 \\
\hline
\end{tabular}

${ }^{*} P$-values indicate the significance of the differences among parental FINDRISC categories

Figures sharing the same superscript letters differentiate significantly from each other

FINDRISC Finnish Diabetes Risk Score, HICs High-income countries, LMICs Low to middle-income countries 
any glycaemia testing, most likely because of their relatively young age, lack of other risk factors or lack of awareness [41].

Prevalence of high BP was comparable with other studies conducted in European countries [42-44], although with large variations among countries, sexes or SES groups (relevant data from the Feel4Diabetes-study are not presented in the current paper). In correspondence with the prevalence of T2D and prediabetes by FINDRISC category observed in the current study, a similar trend was also reported for hypertension and high normal BP, with the prevalence being higher in the higher FINDRISC categories. Indeed, data from a prospective study has shown that FINDRISC can also identify subjects at high risk for developing hypertension in the long-term [45]. Furthermore, in the Feel4Diabetes-study a high proportion $(\approx 80.0 \%)$ of the individuals identified with hypertension was not receiving any antihypertensive treatment. Similar high percentages have been previously reported from population studies [46]. Based on available literature [46, 47], probably many individuals were not aware of their condition, but this can only be speculated in the current study, since the awareness of having hypertension/ high BP was not assessed. Last but not least, individuals that had taken medications for high blood pressure on a regular basis at some point in their life, scored higher in the FINDRISC. This could probably explain why the proportion of undetected cases of hypertension among the individuals identified with hypertension was lower in the highest FINDRISC category.

Finally, about $30 \%$ of the children from the families participating in the second-stage screening were overweight or obese, with this percentage being higher in families that at least one parent was at higher-risk for T2D based on self-reported FINDRISC data. Overall, more than $70 \%$ of the parents attending the secondstage screening were found to be overweight or obese. Given the positive association between parental and children's weight status [48], the implementation of a lifestyle intervention targeting the whole family could have multiple benefits for both high-risk parents and their offspring. Emphasizing to parents that serve as role models for their children [49], could further motivate them to apply lifestyle changes for their own benefit, as well as for the benefit of their children.

\section{Conclusions}

The findings of the current work demonstrate that the systematic, two-stage screening procedure implemented in the Feel4Diabetes-study using the school as the entrypoint to the community can identify individuals and families at high risk for T2D and /or hypertension. Furthermore, considering the relatively young age of the adult participants/parents in the current study, a large proportion of undetected T2D and/or hypertension was also identified. As the current approach is easy-to-apply and with relatively low cost, it could be considered potentially scalable and sustainable for the early identification of high-risk individuals and families (also within vulnerable population-groups), and support initiatives for the prevention of T2D and hypertension.

\section{Abbreviations}

BMI: Body Mass Index; BP: Blood Pressure; FINDRISC: Finnish Diabetes Risk Score; FPG: Fasting plasma glucose; HICs: High-income countries; LMICs: Low to middle-income countries; T2D: Type 2 Diabetes

\section{Acknowledgements}

The authors would like to thank the members of the Feel4Diabetes-study group: Coordinator: Yannis Manios, Steering Committee: Yannis Manios, Greet Cardon, Jaana Lindström, Peter Schwarz, Konstantinos Makrilakis, Lieven Annemans, Ignacio Garamendi, Harokopio University (Greece): Yannis Manios, Meropi Kontogianni, Odysseas Androutsos, Christina Mavrogianni, Konstantina Tsoutsoulopoulou, Christina Katsarou, Eva Karaglani, Irini Qira, Efstathios Skoufas, Konstantina Maragkopoulou, Antigone Tsiafitsa, Irini Sotiropoulou, Michalis Tsolakos, Effie Argyri, Mary Nikolaou, Eleni-Anna Vampouli, Christina Filippou. Katerina Gatsiou, Efstratios Dimitriadis, National Institute for Health and Welfare (Finland): Jaana Lindström, Tiina Laatikainen, Katja Wikström, Jemina Kivelä, Päivi Valve, Esko Levälahti, Eeva Virtanen, Ghent University (Belgium): Department of Movement and Sports Sciences: Greet Cardon, Vicky Van Stappen, Nele Huys; Department of Public Health: Lieven Annemans, Ruben Willems; Department of Endocrinology and Metabolic Diseases: Samyah Shadid, Technische Universität Dresden (Germany): Peter Schwarz, Ivonne Panchyrz, Maxi Holland, Patrick Timpel, National and Kapodistrian University of Athens (Greece): Konstantinos Makrilakis, Stavros Liatis, George Dafoulas, Christina-Paulina Lambrinou, Angeliki Giannopoulou, Lydia Tsirigoti, Evi Fappa, Costas Anastasiou, Konstantina Zachari, International Diabetes Federation Europe (Belgium): Lala Rabemananjara, Maria Stella de Sabata, Winne Ko, Ignacio Garamendi, Universidad De Zaragoza (Spain): Luis Moreno, Fernando Civeira, Gloria Bueno, Pilar De Miguel-Etayo, Esther Ma Gonzalez-Gil, Maria I Mesana, Germán Vicente-Rodriguez, Gerardo Rodriguez, Lucia BailaRueda, Ana Cenarro, Estíbaliz Jarauta, Rocío Mateo-Gallego, Medical University of Varna (Bulgaria): Violeta lotova, Tsvetalina Tankova, Natalia Usheva, Kaloyan Tsochev, Nevena Chakarova, Sonya Galcheva, Rumyana Dimova, Yana Bocheva, Zhaneta Radkova, Vanya Marinova, Yuliya Bazdarska, Tanya Stefanova, University of Debrecen (Hungary): Imre Rurik, Timea Ungvari, Zoltán Jancsó, Anna Nánási, László Kolozsvári, Csilla Semánova, Extensive Life Oy (Finland): Remberto Martinez, Marcos Tong, Kaisla Joutsenniemi, Katrina Wendel-Mitoraj.

\section{About this supplement}

This article has been published as part of BMC Endocrine Disorders, Volume 20 Supplement 1, 2020: Designing, implementing and evaluating a community-based intervention to prevent diabetes in vulnerable families across Europe. The Feel4Diabetes-study. The full contents of the supplement are available at https://bmcendocrdisord.biomedcentral.com/articles/ supplements/volume-20-supplement-1.

\section{Authors' contributions}

YM and CM conducted the data analysis and wrote the first draft of the manuscript. YM, CM, CPL, GC, JL, VI, TT, FC, JK, ZJ, SS, KT, RMG, SR, GD, KM and $\mathrm{OA}$ contributed in the study design, critically revised the manuscript and approved the final manuscript.

\section{Funding}

Publication of this supplement was funded by the Feel4Diabetes-study which has received funding from the European Union's Horizon 2020 research and innovation programme Grant Agreement: $n^{\circ}$ 643708. The content of this article reflects only the authors' views and the European Community is not liable for any use that may be made of the information contained therein. The funding body had no role in the design of this study and collection, analysis, and interpretation of data and in writing this manuscript. 
For the current research work CM was supported by the Hellenic Foundation for Research and Innovation (HFRI) and the General Secretariat for Research and Technology (GSRT), under the HFRI PhD Fellowship grant (GA. no. 466; 133218/I2; 04/08/2017).

\section{Availability of data and materials}

The datasets generated and/or analysed during the current study are not publicly available, since the data used is confidential based on Feel4Diabetes publications rules, but are available from the corresponding author on reasonable request.

\section{Ethics approval and consent to participate}

The Feel4Diabetes-study adhered to the Declaration of Helsinki and the conventions of the Council of Europe on human rights and biomedicine. All participating countries obtained ethical clearance from the relevant ethical committees and local authorities. More specifically, in Belgium the study was approved by the Medical Ethics Committee of the Ghent University Hospital; in Bulgaria, by the Ethics Committee of the Medical University of Varna and the Municipalities of Sofia and Varna, as well as the Ministry of Education and Science local representatives; in Finland, by the hospital district of Southwest Finland ethical committee; in Greece, by the Bioethics Committee of Harokopio University and the Greek Ministry of Education; in Hungary, by the National Committee for Scientific Research in Medicine; and in Spain, by the Clinical Research Ethics Committee and the Department of Consumers' Health of the Government of Aragón. All participants gave their written informed consent prior to their enrolment in the study.

\section{Consent for publication}

Not applicable.

\section{Competing interests}

$\mathrm{OA}$ is a member of the Editorial Board of BMC Endocrine Disorders. He also acted as Guest Editor in the current Supplement Issue. None of the rest of the authors has any conflict to declare.

\section{Author details}

'Department of Nutrition and Dietetics, School of Health Science and Education, Harokopio University, 70 El Venizelou Ave, 17671 Kallithea, Athens, Greece. ${ }^{2}$ Department of Movement and Sports Sciences, Faculty of medicine and Health Sciences, Ghent University, Ghent, Belgium.

${ }^{3}$ Department of Public Health Solutions, National Institute for Health and Welfare, Helsinki, Finland. ${ }^{4}$ Department of Paediatrics, Medical University Varna, Varna, Bulgaria. ${ }^{5}$ Department of Diabetology, Clinical Center of Endocrinology, Medical University Sofia, Sofia, Bulgaria. ${ }^{6}$ Growth, Exercise, Nutrition and Development Research Group, School of Health Science, University of Zaragoza, Zaragoza, Spain. ${ }^{7}$ Department of Family and Occupational Medicine, University of Debrecen, Debrecen, Hungary. ${ }^{8}$ Department of Endocrinology, Ghent University Hospital, Ghent, Belgium. ${ }^{9}$ Instituto de Investigación Sanitaria Aragón (IIS Aragón), CIBERCV, Zaragoza, Spain. ${ }^{10}$ National and Kapodistrian University of Athens, Athens, Greece.

${ }^{11}$ Department of Nutrition and Dietetics, School of Physical Education, Sport Science and Dietetics, University of Thessaly, Trikala, Greece.

\section{Received: 18 November 2019 Accepted: 19 December 2019} Published: 12 March 2020

\section{References}

1. International Diabetes Federation (IDF) Diabetes Atlas 8th Edition (2017) https://www.idf.org/e-library/epidemiology-research/diabetes-atlas.html Accessed 18 Oct 2019

2. Global Burden of Metabolic Risk Factors for Chronic Diseases Collaboration. Cardiovascular disease, chronic kidney disease, and diabetes mortality burden of cardiometabolic risk factors from 1980 to 2010: a comparative risk assessment. Lancet Diabetes Endocrinol. 2014;2(8):634-47.

3. Agardh E, Allebeck P, Hallqvist J, Moradi T, Sidorchuk A. Type 2 diabetes incidence and socio-economic position: a systematic review and metaanalysis. Int J Epidemiol. 2011;40(3):804-18.

4. Bilal U, Auchincloss AH, Diez-Roux AV. Neighborhood environments and diabetes risk and control. Curr Diabetes Rep. 2018;18(9):62.

5. Sacerdote C, Ricceri F, Rolandsson O, Baldi I, Chirlaque MD, Feskens E, et al. Lower educational level is a predictor of incident type 2 diabetes in
European countries: the EPIC-InterAct study. Int J Epidemiol. 2012;41(4): 1162-73.

6. Tuomilehto J, Lindstrom J, Eriksson JG, Valle TT, Hamalainen H, llanneParikka $\mathrm{P}$, et al. Prevention of type 2 diabetes mellitus by changes in lifestyle among subjects with impaired glucose tolerance. N Engl J Med. 2001; 344(18):1343-50.

7. Knowler WC, Barrett-Connor E, Fowler SE, Hamman RF, Lachin JM, Walker EA, et al. Reduction in the incidence of type 2 diabetes with lifestyle intervention or metformin. N Engl J Med. 2002;346(6):393-403.

8. Herman WH, Ye W, Griffin SJ, Simmons RK, Davies MJ, Khunti K, et al. Early detection and treatment of type 2 diabetes reduce cardiovascular morbidity and mortality: a simulation of the results of the Anglo-Danish-Dutch study of intensive treatment in people with screen-detected diabetes in primary care (ADDITION-Europe). Diabetes Care. 2015;38(8):1449-55.

9. Simmons RK, Griffin SJ, Lauritzen T, Sandbaek A. Effect of screening for type 2 diabetes on risk of cardiovascular disease and mortality: a controlled trial among 139,075 individuals diagnosed with diabetes in Denmark between 2001 and 2009. Diabetologia. 2017;60(11):2192-9.

10. Craigie AM, Lake AA, Kelly SA, Adamson AJ, Mathers JC. Tracking of obesityrelated behaviours from childhood to adulthood: a systematic review. Maturitas. 2011;70(3):266-84.

11. Lloyd $\sqcup$, Langley-Evans SC, McMullen S. Childhood obesity and risk of the adult metabolic syndrome: a systematic review. Int J Obes (2005). 2012;36(1):1-11.

12. Golan M. Parents as agents of change in childhood obesity from research to practice. Int Pediatr Obes. 2006;1(2):66-76.

13. Baig AA, Benitez A, Quinn MT, Burnet DL. Family interventions to improve diabetes outcomes for adults. Ann N Y Acad Sci. 2015;1353:89-112.

14. Khunti K, Gillies CL, Taub NA, Mostafa SA, Hiles SL, Abrams KR, et al. A comparison of cost per case detected of screening strategies for type 2 diabetes and impaired glucose regulation: modelling study. Diabetes Res Clin Pract. 2012;97(3):505-13.

15. Khunti K, Mani H, Achana F, Cooper N, Gray LJ, Davies MJ. Systematic review and meta-analysis of response rates and diagnostic yield of screening for type 2 diabetes and those at high risk of diabetes. PLoS One. 2015;10(9):e0135702.

16. International Diabetes Federation (IDF). Recommendations For Managing Type 2 Diabetes In Primary Care (2017) https://www.idf.org/e-library/ guidelines/128-idf-clinical-practice-recommendations-for-managing-type-2diabetes-in-primary-care.html. Accessed 18 Oct 2019.

17. Ryden L, Grant PJ, Anker SD, Berne C, Cosentino F, Danchin N, et al. ESC guidelines on diabetes, pre-diabetes, and cardiovascular diseases developed in collaboration with the EASD: the task force on diabetes, pre-diabetes, and cardiovascular diseases of the European Society of Cardiology (ESC) and developed in collaboration with the European Association for the Study of diabetes (EASD). Eur Heart J. 2013;34(39):3035-87.

18. Lindstrom J, Tuomilehto J. The diabetes risk score: a practical tool to predict type 2 diabetes risk. Diabetes Care. 2003;26(3):725-31.

19. Sargeant LA, Simmons RK, Barling RS, Butler R, Williams KM, Prevost AT, et al Who attends a UK diabetes screening programme? Findings from the ADDITION-Cambridge study. Diabetic Med. 2010;27(9):995-1003.

20. Tsimihodimos V, Gonzalez-Villalpando C, Meigs JB, Ferrannini E. Hypertension and Diabetes Mellitus: Coprediction and Time Trajectories. Hypertension (Dallas, Tex : 1979). 2018;71(3):422-8.

21. Manios Y, Androutsos O, Lambrinou CP, Cardon G, Lindstrom J, Annemans $L$, et al. A school- and community-based intervention to promote healthy lifestyle and prevent type 2 diabetes in vulnerable families across Europe: design and implementation of the Feel4Diabetes-study. Public Health Nutr. 2018;21(17):3281-90.

22. World Bank Group. World Development Indicators 2014. Washington, DC: World Bank Publications; 2014.

23. Eurostat. Euro Area and EU28 Government Deficit at 0.9 and $1.0 \%$ of GDP Respectively. Luxembourg: Eurostat; 2018.

24. NCD Risk Factor Collaboration (NCD-RisC). Worldwide trends in diabetes since 1980: a pooled analysis of 751 population-based studies with 4.4 million participants. Lancet (London, England). 2016;387(10027):1513-30.

25. Hellenic Statistical Authority (ELSTAT) https://wnw.statistics.gr/ Accessed 18 Oct 2019.

26. VDAB-Arvastat. https://arvastat.vdab.be/arvastat_basisstatistieken_ werkloosheid.html. Accessed 18 Oct 2019.

27. Statistics Finland's PxWeb databases http://pxnet2.stat.fi/PXWeb/pxweb/en/ StatFin/StatFin vrm vaerak/?rxid=6b89654c-24b1-4509-816f-80b00b6e4 97f. Accessed 18 Oct 2019 
28. Instituto Aragonés de Estadística (IAEST) https://www.aragon.es/en/ organismos/departamento-de-economia-planificacion-y-empleo/direcciongeneral-de-economia/instituto-aragones-de-estadistica-iaest-. Accessed 18 Oct 2019.

29. Costas A, Fappa E, Zachari K, Mavrogianni C, Van Stappen V, Kivelä J, Virtanen E, González-Gil E, Flores Barrantes P, Nánási A, Semánová C, Dimova R, Usheva N, lotova V, Greet C, Manios Y, Makrilakis K. Development and reliability of questionnaires for the assessment of diet and physical activity behaviors in a multi-country sample in Europe the Feel4Diabetes Study [paper published supplement].

30. Androutsos O, Costas A, Lambrinou C-P, Mavrogianni C, Cardon G, Van Stappen V, Kivelä J, Wikström K, Moreno LA, lotova V, Tsochev K, Chakarova $\mathrm{N}$, Ungvári T, Jancso Z, Makrilakis $K$, Manios $Y$, on behalf of the Feel4diabetes-study group. Intra- and inter- observer reliability of anthropometric measurements and blood pressure in primary schoolchildren and adults. The Feel4Diabetes-study [paper published in the current supplement].

31. https://www.diabetes.fi/files/502/eRiskitestilomake.pdf. Assessed 18 Oct 2019.

32. Cole TJ, Lobstein T. Extended international (IOTF) body mass index cut-offs for thinness, overweight and obesity. Pediatric obesity. 2012;7(4):284-94.

33. American Diabetes Association. 2. Classification and Diagnosis of Diabetes: Standards of Medical Care in Diabetes-2018. Diabetes Care. 2018;41(Suppl 1):S13-s27.

34. Williams B, Mancia G, Spiering W, Agabiti Rosei E, Azizi M, Burnier M, et al. 2018 ESC/ESH guidelines for the management of arterial hypertension: the task force for the management of arterial hypertension of the European Society of Cardiology and the European Society of Hypertension: the task force for the management of arterial hypertension of the European Society of Cardiology and the European Society of Hypertension. J Hypertens. 2018; 36(10):1953-2041.

35. WHO. Obesity: preventing and managing the global epidemic Report of a WHO Consultation. Geneva: WHO; 2000

36. Simmons D, Zgibor JC. Should we screen for type 2 diabetes among asymptomatic individuals? Yes. Diabetologia. 2017;60(11):2148-52.

37. Gagliardino JJ, Elgart JF. Diabetes primary prevention program: New insights from data analysis of recruitment period. Diabetes Metab Res Rev. 2018; 34(1):e2943.

38. Cos FX, Barengo NC, Costa B, Mundet-Tuduri X, Lindstrom J, Tuomilehto JO. Screening for people with abnormal glucose metabolism in the European DE-PLAN project. Diabetes Res Clin Pract. 2015;109(1):149-56.

39. Franciosi M, De Berardis G, Rossi MC, Sacco M, Belfiglio M, Pellegrini F, et al. Use of the diabetes risk score for opportunistic screening of undiagnosed diabetes and impaired glucose tolerance: the IGLOO (impaired glucose tolerance and long-term outcomes observational) study. Diabetes Care. 2005;28(5):1187-94.

40. Mavrogianni C, Lambrinou CP, Androutsos O, Lindstrom J, Kivela J, Cardon $\mathrm{G}$, et al. Evaluation of the Finnish diabetes risk score as a screening tool for undiagnosed type 2 diabetes and dysglycaemia among early middle-aged adults in a large-scale European cohort. The Feel4Diabetes-study. Diabetes Res Clin Pract. 2019;150:99-110.

41. Casagrande SS, Cowie CC, Genuth SM. Self-reported prevalence of diabetes screening in the U.S., 2005-2010. Am J Prev Med. 2014;47(6): 780-7.

42. Psaltopoulou T, Orfanos P, Naska A, Lenas D, Trichopoulos D, Trichopoulou A. Prevalence, awareness, treatment and control of hypertension in a general population sample of 26,913 adults in the Greek EPIC study. Int J Epidemiol. 2004;33(6):1345-52.

43. Wagner A, Sadoun A, Dallongeville J, Ferrieres J, Amouyel P, Ruidavets JB, et al. High blood pressure prevalence and control in a middle-aged French population and their associated factors: the MONA LISA study. J Hypertens. 2011;29(1):43-50.

44. Tocci G, Nati G, Cricelli C, Parretti D, Lapi F, Ferrucci A, et al. Prevalence and control of hypertension in the general practice in Italy: updated analysis of a large database. J Hum Hypertens. 2017;31(4):258-62.

45. Fizelova M, Jauhiainen $R$, Stancakova A, Kuusisto J, Laakso M. Finnish diabetes risk score is associated with impaired insulin secretion and insulin sensitivity, drug-treated hypertension and cardiovascular disease: a follow-up study of the METSIM cohort. PLoS One. 2016;11(11):e0166584.

46. Pereira M, Lunet N, Azevedo A, Barros H. Differences in prevalence, awareness, treatment and control of hypertension between developing and developed countries. J Hypertens. 2009;27(5):963-75.
47. Chow CK, Teo KK, Rangarajan S, Islam S, Gupta R, Avezum A, et al. Prevalence, awareness, treatment, and control of hypertension in rural and urban communities in high-, middle-, and low-income countries. Jama. 2013;310(9):959-68.

48. Wang Y, Min J, Khuri J, Li M. A Systematic Examination of the Association between Parental and Child Obesity across Countries. Adv Nutr (Bethesda, Md). 2017;8(3):436-48

49. Ritchie LD, Welk G, Styne D, Gerstein DE, Crawford PB. Family environment and pediatric overweight: what is a parent to do? J Am Diet Assoc. 2005; 105(5 Suppl 1):S70-9.

\section{Publisher's Note}

Springer Nature remains neutral with regard to jurisdictional claims in published maps and institutional affiliations.
Ready to submit your research? Choose BMC and benefit from:

- fast, convenient online submission

- thorough peer review by experienced researchers in your field

- rapid publication on acceptance

- support for research data, including large and complex data types

- gold Open Access which fosters wider collaboration and increased citations

- maximum visibility for your research: over $100 \mathrm{M}$ website views per year

At BMC, research is always in progress.

Learn more biomedcentral.com/submissions 